Volume 2

Number 1

Spring 2002

ISSN 1472-6696

JOURNAL OF THE BRITISH AND IRISH ASSOCIATION OF LAW LIBRARIANS

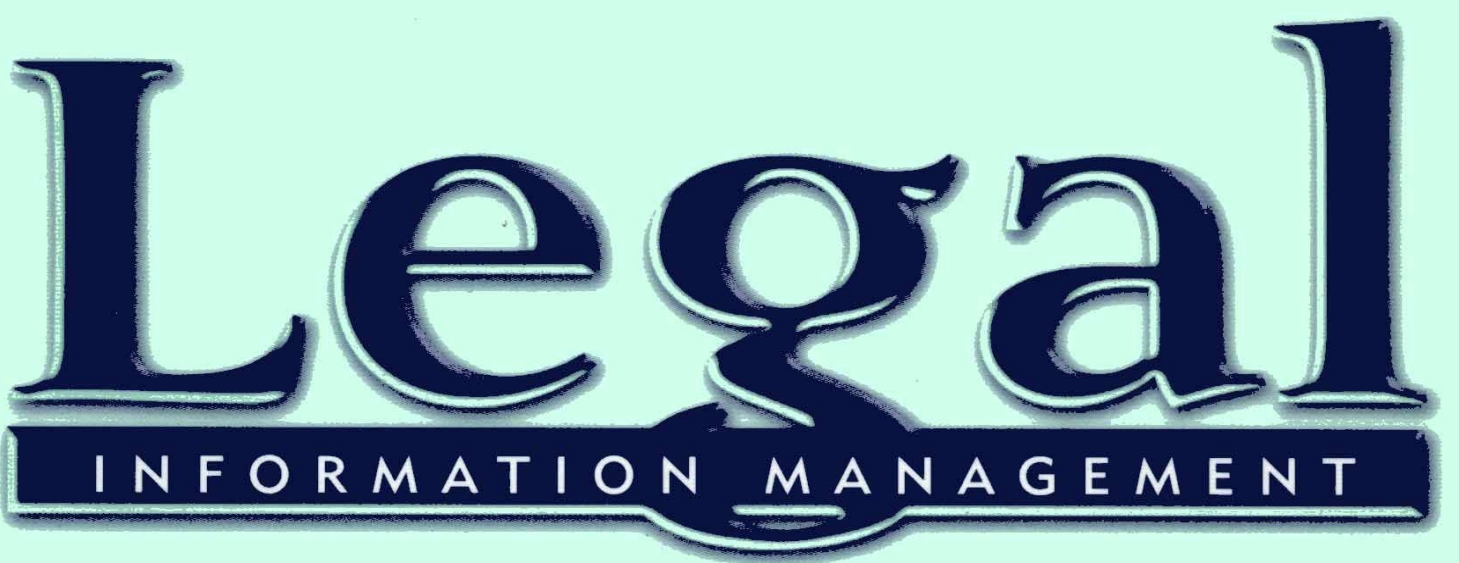

- In Memoriam: Betty Moys

- Knowledge management:

$B M+I M=K M$

- Taxonomies

- Digitisation: Do we have a strategy?

- Current Awareness 


\section{A refreshing necessity...}

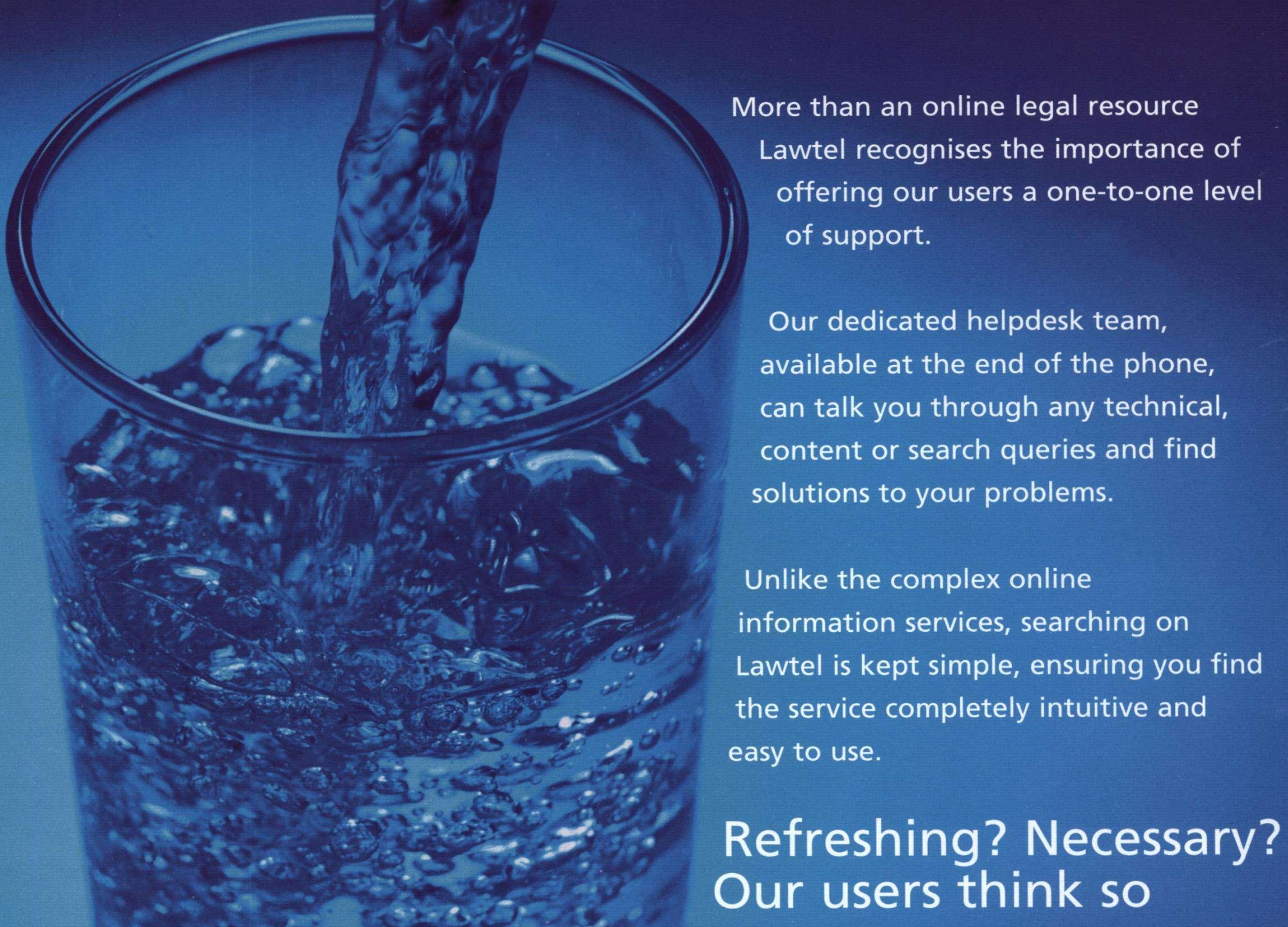

Try us and see... For a free 7-day trial... Call 02079704818

E-mail enquiries@lawtel.com

www.lawtel.com

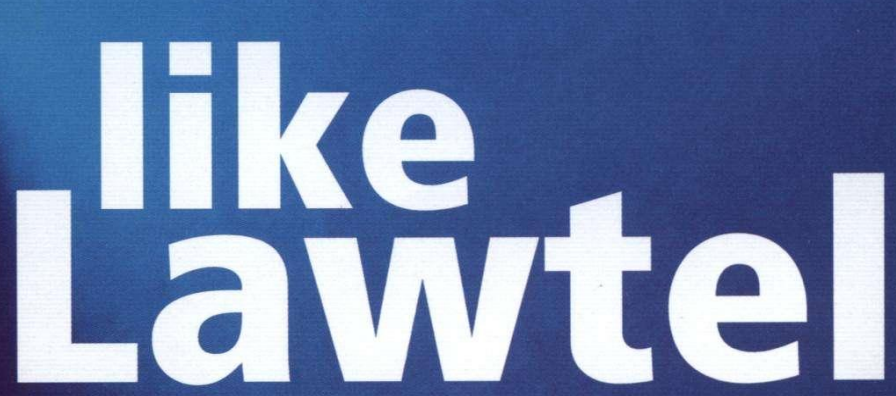

:The 
Journal of the British and Irish Association of Law Libraries

2

In Memoriam:

Elizabeth Mary Moys 1928 to 2002

Barbara Tearle, President, BIALL

$B M+I M=K M$

Lesley Robinson

Intranets and Extranets in Law Firms

Martın White, Intranet Focus Ltd

Taxonomies

Christine Miskin, Granite \& Comfrey

"And I still haven't found what I'm looking for:"

Simon Atkinson, Verity GB Ltd

Automatic Link Creation within Legal Documents

Dr Justine Needle, Context Limited

Legal Information Services in South Africa

Olwyn Garratt, Faırbridge Arderne \& Lawton

Publishing a Book: A Moral Tale

Caroline Humphries, CMS Cameron McKenna

Digitisation: Do We Have a Strategy?

David Pearson, Wellcome Library

Discovering Columbus

Sean Barr, University of Swansea

Current Awareness

David Gee and June Tomlinson, Institute of Advanced Legal Studies

IT in the Law

Laurence W. Bebbington, University of Nottingham

52

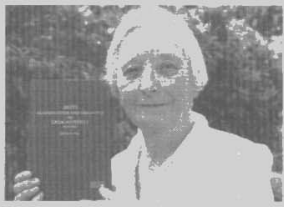

8

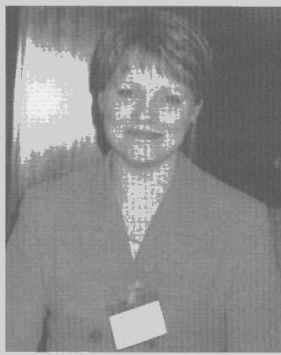

24

26

30

33

35

40

46
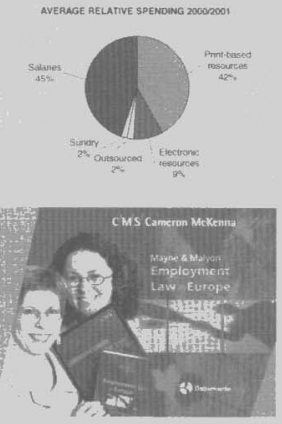

E-Product Review

56

Siobban Heaney, Infoconsult

Book Reviews

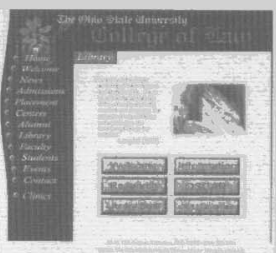

